\title{
Respuesta a las críticas
}

\author{
Martín Hevia
}

Resumen: El texto responde a críticas realizadas por Diego Papayannis, De la Maza Gazmuri y Rengifo Gardeazábal en esta misma revista al artículo: "Razonabilidad y Responsabilidad: Rawls, Kant y la teoría del derecho contractual".

Palabras clave: derecho contractual, responsabilidad, razonabilidad.

\begin{abstract}
Diego Papayannis, Íñigo de la Maza Gazmuri y Mauricio Rengifo Gardeazábal in this review to the essay "Reasonableness and Responsibility: A Theory of Contract Law".
\end{abstract}

Key words: contractual law, responsibility, reasonableness.

\section{Palabras preliminares}

Agradezco muchísimo la oportunidad de discutir en este foro mi artículo, que trata los puntos centrales de mi libro Reasonableness and Responsibility. En especial, quisiera agradecer a Diego Papayannis por proponer a los editores de Discusiones este intercambio y por el esfuerzo para que se hiciera real. Agradezco a Lucas Grosman por coordinar y editar este intercambio. Me siento honrado por los comentarios de los profesores De la Maza Gazmuri, Papayannis y Rengifo Gardeazábal, cuyo trabajo admiro ${ }^{1}$. Sus trabajos abordan diferentes aspectos de mi

1 Diego Papayannis y yo hemos conversado mucho, en los últimos años, acerca de la teoría del derecho privado. Nos hemos hecho amigos después de tantas conversaciones. Sus trabajos sobre la metodología de la filosofía del derecho privado y del análisis económico del derecho han tenido una fuerte influencia 
Martín Hevia

artículo. Sin dudas, me han hecho pensar nuevamente tanto en los fundamentos como en los detalles de mi teoría. En este artículo espero ser justo con los comentarios. El lector notará que algunos de ellos me han llevado a revisar mi trabajo y, finalmente, a proponer un alcance nuevo a mi posición.

\section{II.Introducción}

Quisiera comenzar mi respuesta partiendo de uno de los comentarios de De la Maza Gazmuri, quien ${ }^{2}$ se pregunta en qué sentido empleo la expresión "teoría"3. Esta observación es una oportunidad para poner en contexto algunas de las objeciones presentadas por los tres comentaristas.

En el comienzo de su artículo, De la Maza Gazmuri sigue la taxonomía propuesta por Stephen Smith en Contract Theory y explica que, a su juicio, mi teoría no es ni histórica, ni descriptiva, ni prescriptiva; que, en cambio, mi teoría es "interpretativa" porque "nos sugiere una idea a partir de la cual resulta posible agudizar nuestra comprensión del

en la metodología que sigo en mis trabajos. Ver, por ejemplo, Papayannis D., "Teorías de la Responsabilidad Extracontractual", en Hevia, M., Teoría y Crítica del Derecho Civil y Comercial, Fontamara, México, 2012. Los trabajos de Íñigo de la Maza Gazmuri sobre los contratos de adhesión me han ayudado a comprender mejor un área del derecho; sus textos, de hecho, son lectura obligatoria en los cursos de contratos que he dictado. Ver, en particular, De la Maza Gazmuri, I., "Contratos por adhesión y cláusulas abusivas: ¿por qué el estado y no solamente el mercado? Revista Chilena de Derecho Privado Fernando Fueyo Laneri, 2003. A su vez, Rengifo Gardeazábal es autor de Teoría General de la Propiedad, una obra en la que el lector encontrará el análisis más iluminador que conozco sobre el concepto de propiedad en la tradición continental de derecho privado. Ver Rengifo Gardeazábal, M., Teoría General de la Propiedad. Bogotá, Temis, 2011.

2 Smith, S., Contract Theory, Cambridge, Oxford University Press, 2004, pág. 4. El libro de Smith es una de las obras esenciales e imperdibles de la teoría del derecho contractual.

3 De la Maza Gazmuri, I., "Razonabilidad y responsabilidad: A propósito de la teoría del derecho contractual del profesor Martín Hevia". Discusiones, XV, 2014, págs. 85-100. 
derecho de contratos, pus nos revela un orden inteligible que subyace al diseño de sus normas" 4 . La observación es muy acertada; de hecho, ni en mi libro ni en el artículo de esta discusión, expliqué qué sentido le otorgaba a la expresión "teoría". El comentario, entonces, es una oportunidad para explicar mejor el alcance de mi trabajo.

Por empezar, en efecto, mi teoría no es histórica, es decir, no tiene por objetivo explicar cuáles son las causas de la existencia del derecho contractual y de cómo se ha desarrollado. Así, por ejemplo, como explica Smith, un autor que explique las instituciones del derecho contractual como consecuencia de fuerzas de producción cambiantes en los siglos XVIII y XIX adoptaría una explicación histórica. Muy probablemente, este enfoque es el que adoptaría un historiador del derecho. James Gordley, por ejemplo, sostiene que el derecho contractual que hoy tenemos es consecuencia de las preocupaciones de los juristas medievales por desarrollar un sistema jurídico virtuoso ${ }^{5}$. Mi teoría tampoco es meramente descriptiva, es decir, no es como la mayoría de los manuales de derecho contractual que, en general, carecen de vocación crítica o normativa. Una teoría prescriptiva presenta un ideal acerca de cómo debería ser el derecho. Así, entonces, si un jurista sostiene que el derecho debe promover la eficiencia y, por lo tanto, que las instituciones jurídicas deben diseñarse en función de ese ideal, estamos ante una teoría normativa del derecho contractual ${ }^{6}$. Así, por ejemplo, un defensor de dicho ideal podría proponer la eliminación de alguna norma porque genera un estado de cosas ineficiente - por ejemplo, podría proponer modificar

4 Ídem.

5 Smith, S., op. cit., pág. 4. De hecho, la obra de Gordley como historiador del derecho privado es muy iluminadora. Por ejemplo, Gordley explica magistralmente el origen aristotélico del concepto de "causa", que utilizan los sistemas de derecho privado de raíz continental- europea. En mi calidad de profesor de derecho privado, los textos de Gordley me han sido de mucha utilidad para comprender y explicar mejor el derecho privado. Ver, por ejemplo, Gordley, J., Foundations of Private Law, Cambridge: Oxford University Press, 2006 y Gordley, J., The Philosophical Origins of Modern Contract Doctrine, Cambridge: Oxford University Press, 1991.

6 Smith,S., op. cit., págs. 4-5. 
Martín Hevia

la norma que obliga a celebrar por escrito determinados contratos, o la regla de la consideration del common law-. Finalmente, como explica Gazmuri, mi teoría es interpretativa porque se propone iluminar o encontrarle un sentido al derecho contractual ${ }^{7}$. Así, por ejemplo, la idea de que las doctrinas fundamentales del derecho de los contratos reflejan una concepción de la reciprocidad es parte de una teoría interpretativa. Smith también explica que defender una teoría interpretativa no implica una crítica de otros tipos de teorías; los historiadores y los filósofos del derecho tienen proyectos de investigación con objetos diferentes. Es más, para "encontrarle un sentido al derecho" (make sense of law) las teorías interpretativas deben incluir elementos históricos, descriptivos y prescriptivos. Por ejemplo, si sabemos que, al resolver controversias contractuales, los jueces no tienen en cuenta consideraciones económicas $-\mathrm{O}$, al menos, que no las manifiestan por escrito en sus sentencias-, entonces no tendría mucho sentido sostener que el derecho contractual vigente puede entenderse mejor a la luz del valor "eficiencia económica". Una teoría del derecho contractual debe reflejar lo que famosamente H.L.A. Hart llamó "el punto de vista interno" de los agentes que participan en la práctica. Smith también explica la relación entre las teorías prescriptivas y las interpretativas. Por un lado, para reformar el derecho desde alguna perspectiva que se quiera promover, es necesario entender el derecho que se desea reformar. Por otro lado, al diseñar las reglas del derecho contractual, los legisladores presuntamente piensan que el derecho debe tener una justificación moral. Esa justificación puede ser incorrecta, pero es razonable asumir que, al menos en teoría, el derecho vigente debería parecerse a lo que idealmente debería ser el derecho ${ }^{8}$.

En este trabajo, identificaré dos tipos de objeciones desarrolladas por mis comentaristas, relacionadas con la naturaleza interpretativa de mi teoría. Por un lado, Papayannis y Rengifo Gardeazábal presentan dudas acerca de la filosofía política que sirve de base a la teoría del derecho contractual que propongo. En la primera parte de este trabajo

7 De la Maza Gazmuri, "Razonabilidad y responsabilidad...", op. cit. 8 Smith, S., op. cit., pág. 6. 
me concentraré en ese tipo de objeciones. Por otro lado, los tres comentaristas sostienen que mi teoría no da cuenta del derecho contractual como lo conocemos actualmente. Dado que mi teoría es una teoría interpretativa, si las objeciones son correctas, la teoría debe revisarse. En la segunda parte de este trabajo me concentro en responder a estas objeciones. Concluiré que algunas de ellas son apropiadas. Por consiguiente, servirán como puntapié para revisar aspectos fundamentales de la teoría que desarrollo en Reasonableness and Responsibility.

\section{Primera parte. Derecho contractual y filosofía política: respuesta a Papayannis y a Rengifo Gardeazábal}

\section{III.1. Libertarismo y derecho contractual}

La primera objeción de Papayannis es que mi rechazo general de las teorías monistas para comprender el derecho contractual no está justificado. Según Papayannis, las diferencias con los libertarios "se remontan a la teoría subyacente de los derechos...", pero mi teoría del derecho contractual no sería rechazada por los libertarios: tanto para mi teoría como para los libertarios, "los contratos... definen las condiciones en las que los individuos pueden transferirse mutuamente recursos o derechos" ". Así,

[1]a única diferencia entre la concepción libertaria y la que ofrece Hevia es que para los primeros el derecho natural sobre el propio cuerpo y el fruto de su trabajo determina que la distribución sea un paso previo a la cooperación... mientras que para los rawlsianos la cooperación social tiene prioridad conceptual y, por ello, debe implementarse un esquema razonable para repartir los beneficios de esa cooperación ${ }^{10}$.

9 Papayannis, D., "La insoportable levedad de la justicia correctiva en el derecho contractual". Discusiones, XV, 2014, págs. 101-144.

10 Ídem. 
Martín Hevia

En respuesta a Papayannis, podría decir que mi argumento no es que si "concepción del derecho contractual" se refiere al conjunto de normas y doctrinas propias del derecho de los contratos, mi concepción del derecho contractual es diferente de la libertaria. Es cierto que muchos libertarios bien podrían estar de acuerdo con mi teoría. Ciertamente, como bien explica Papayannis, compartirían la visión del derecho contractual como una herramienta de la que disponen las personas para intercambiar bienes y servicios mediante su consentimiento. De hecho, en mi contribución a este número, sostengo que "a diferencia de los distributivistas, dado el énfasis que hacen en la idea de libertad, los libertarios sí pueden explicar por qué los contratos son interacciones privadas". Aprovecharé esta oportunidad para extenderme más en la crítica al libertarismo que desarrollo en el capítulo 3 de Reasonableness and Responsibility.

Como bien explica Papayannis, mi crítica no está dirigida a la teoría libertaria del derecho contractual, sino a la defensa que los libertarios - $\mathrm{O}$, al menos, Robert Nozick — hacen de la libertad contractual como elemento distintivo de su filosofía política. Los libertarios sostienen que su teoría es consistente con tomar en serio la autonomía de las personas para utilizar sus recursos del modo en que prefieran hacerlo; para ellos, las teorías de la justicia igualitarias, como la de Rawls, no toman en serio a las personas porque, para mantener la igualdad, deben interferir con las transferencias voluntarias para que estas no pongan en peligro el estado del mundo deseable - es decir, el estado de cosas en el que hay una cierta forma de igualdad, según la métrica de igualdad preferida-.

Para Nozick, cualquier principio pautado o de estado final que se adopte acabará por ser alterado por las elecciones libres de las personas: una vez que se deja a las personas utilizar sus recursos como más lo prefieran, se alterará la distribución ideal. En consecuencia, para mantener vigente un principio de justicia pautado o de estado final es necesario interferir constantemente con la libertad de las personas, por ejemplo, prohibiéndoles transferir sus recursos a otras personas.

Dado que no requiere interferir constantemente con las transacciones privadas de los individuos, el libertarismo resulta "más 
amigable" con la libertad. Como dice Nozick, "no está claro cómo aquellos que apoyan concepciones alternativas de la justicia distributiva podrían rechazar la concepción intitular de la justicia en las pertenencias"11.

Mi objeción a la crítica de Nozick es que si "amigable con la libertad" significa que "no interfiere constantemente con el ejercicio de la libertad", entonces es falso que su teoría de la justicia - y, por ende, del derecho de los contratos - sea la única "amigable con la libertad". La teoría de la justicia de Rawls no requiere interferencias constantes en la libertad de las personas porque es "dinámica." Las teorías de la justicia dinámicas son compatibles con diversos esquemas distributivos. Así, según este tipo de teorías, en la medida en que estén en funcionamiento las instituciones apropiadas, el resultado debe ser justo. Por consiguiente, no habría nada de malo si, como consecuencia de intercambios voluntarios, una persona resulta más rica que las demás porque, como explica Rawls, las personas que participan del esquema de cooperación saben que la justicia distributiva opera en otra dimensión del sistema social de cooperación. Las personas sabemos que, eventualmente, nuestro deber de contribuir al sistema de cooperación social puede requerir el pago de impuestos. Pero ello no obsta a que dispongamos libremente de nuestros bienes ${ }^{12}$.

La objeción de Nozick es aplicable a las teorías de la justicia "procesalmente perfectas", es decir, a las teorías que disponen de un criterio independiente para determinar qué estados de cosas o del mundo es el justo y que, sobre esa base, establecen un procedimiento que garantiza que se satisfaga el resultado deseado desde el comienzo. En cambio, las teorías libertarias de la justicia, así como también la teoría de la justicia de Rawls, son teorías "procesalmente puras": diseñan un procedimiento que ven como justo; el resultado que se siga de respetar el procedimiento será necesariamente justo, cualquiera sea el resultado.

${ }^{11}$ Nozick, Anarchy, State, and Utopia, Basic Books, Nueva York, 1973, pág. 160.

${ }^{12}$ Hevia, M., "Razonabilidad y responsabilidad...", op. cit. 
Martín Hevia

En suma, Papayannis tiene razón cuando sostiene que los libertarios podrían compartir el diseño del derecho contractual que propongo en el libro. No obstante, como bien lo explica, el fundamento que propongo es diferente del propuesto por los libertarios; es más, si tengo razón, la objeción de los libertarios al tipo de teorías de la justicia distributiva que sirven de base a mi propuesta fracasa.

\section{III.2. Distributivismo y derecho contractual}

La segunda objeción de Papayannis se concentra en mi interpretación de la teoría distributivista de Anthony Kronman. Según este autor, Kronman defiende dos tesis:

1. Para ser válidos, los aprovechamientos recíprocos deben ser moralmente aceptables (los contratos conllevan siempre un aprovechamiento recíproco).

2. El derecho contractual puede ser diseñado para promover objetivos sociales (de distribución, eficiencia u otros posibles). Según Papayannis, esta segunda tesis se reflejaría en las restricciones impuestas a la libertad para establecer el objeto de un contrato que los sistemas jurídicos llaman "de orden público".

Para Papayannis, mi interpretación de Kronman es que la segunda tesis es la más importante de las dos y que los contratos solamente pueden justificarse en la medida en que contribuyan a un estado de cosas socialmente justo. Papayannis sostiene que interpreto a Kronman como si fuera un utilitarista, es decir, como si el paretianismo de Kronman no limitara el análisis paretiano a la clase de personas que consisten la obligación contractual. La lectura que Papayannis hace de Kronman es plausible. En este comentario, no responderé directamente a la cuestión de si su interpretación es más apropiada que la mía. Efectivamente, al revisar mi propia interpretación, entiendo que está basada en la idea de que el carácter igualitario del paretianismo asume que todos los bienes pertenecen a un fondo común. Más adelante en el artículo, me tomaré de la interpretación 
de Papayannis para sugerir que, para dar cuenta de los contratos de consumo, mi propia teoría debe acercarse a la interpretación de Kronman propuesta por Papayannis, en particular, a la primera tesis de Kronman.

Con respecto a la segunda tesis de Kronman, si esta es equivalente al "orden público", entonces también en este contexto es apropiado discutir la idea del Profesor De la Maza Gazmuri, quien en su comentario sostiene que no puede ser cierto que, con la excepción de las personas independientes, todo pueda ser objeto de un contrato. A tal fin, ofrece ejemplos de restricciones habituales al objeto de un contrato, tales como la prohibición de compraventa de ciertas sustancias, o los límites impuestos a la autonomía de las partes por la doctrina de la lesión enorme, o los límites a los liquidated damages en el common law ${ }^{13}$. Podría responder a esta objeción explicando mejor el fundamento de la teoría que propongo. En el libro explico que algunos bienes están fuera del comercio y no pueden ser objeto de obligaciones contractuales. Así, las libertades básicas no pueden intercambiarse ni regalarse ${ }^{14}$. Son "bienes primarios" inalienables. El diseño del derecho contractual debe contemplar este tipo de restricciones. Si ello

13 De la Maza Gazmuri, I., "Razonabilidad y responsabilidad...", op. cit.

${ }^{14}$ En la teoría de la justicia de Rawls, que es la base de mi teoría del derecho contractual, las libertades básicas son "bienes primarios". La lista de bienes primarios es la siguiente:

- las libertades básicas: libertad de pensamiento y libertad de conciencia; libertad de asociación; y la libertad definida por la libertad e integridad de la persona, así como también por el estado de derecho; y, finalmente, las libertades políticas;

- libertad de movimiento y elección de ocupación contra un trasfondo de oportunidades diversas;

- poderes y prerrogativas de oficinas y posiciones de responsabilidad, particularmente aquellas en las principales instituciones políticas y económicas;

- ingresos y riquezas (teniendo un valor de cambio) que se necesitan para alcanzar los diferentes fines que las personas puedan aprobar; y

- las bases sociales del auto-respeto a sí mismo (es decir, cosas como la realidad institucional de que las personas tienen derechos básicos iguales y que todos apoyan las instituciones sociales). 
significa aceptar la segunda tesis de Kronman, entonces, en mi teoría, el derecho contractual efectivamente tiene una dimensión distributiva en el sentido de Kronman.

Como diré más adelante, no obstante, mi teoría no se refiere a otro tipo de restricciones, como las que establece la doctrina de la lesión, que permite que la parte más débil en una relación contractual pueda pedir su nulidad invocando que su contraparte se aprovechó de la situación de inferioridad. Creo que la mayoría de los casos para los que originalmente estaba prevista la doctrina de la lesión hoy quedarían comprendidos en las normas de defensa del consumidor - en general, son casos en los que hay asimetría de información entre oferente y aceptante- Con independencia de si ello es o no, el punto relevante es que mi teoría debería también aceptar la posibilidad de que las personas puedan invocar lesión y que los tribunales les den la razón y anulen o modifiquen las cláusulas de un contrato: al permitir que las víctimas de aprovechamiento puedan pedir la nulidad o la modificación de un contrato, como explica Papayannis, el derecho contractual incluye consideraciones de naturaleza distributiva. Abordaré este punto más adelante al tratar los contratos de consumo.

\section{III.3. E1 reino de los fines y las expectativas razonables}

Rengifo Gardeazábal sostiene que mi posición es profundamente inconsistente porque la concepción objetivista del contrato basada en expectativas razonables "poco o nada tiene que ver con la idea de una sociedad organizada como un reino de fines" 15 . Para Rengifo Gardeazábal, la idea de expectativa razonable se asocia, más bien, a la idea del "hombre promedio o a la idea del espectador imparcial que actúa con información completa"16. Si bien Rengifo Gardeazábal no concentra su crítica en este aspecto de mi teoría — sino en otros

Ver Rawls, J., Justice as Fairness - A Restatement, The Belknap Press of The Harvard University Press, Cambridge, Massachussets, 2001.

15 Rengifo Gardeazábal, M., "Teoría del contrato, libertad y determinismo social: la posición incompatibilista". Discusiones, XV, 2014, págs. 49-84. 
aspectos que discutiré más adelante-, es interesante responder a esta objeción. En primer lugar, el estándar de la persona razonable no es un estándar fáctico sino normativo. Eso significa que no representa a la persona ordinaria o promedio. La idea de la persona razonable está basada en una concepción de la igualdad. En mi trabajo, defiendo la idea de que las personas razonables son iguales en el sentido de que, como explica Rawls, todos tenemos los dos poderes morales, lo que nos permite ser parte de un esquema social de cooperación. Ahora bien, dado que, finalmente, los tribunales son los encargados de poner en práctica este estándar, podría ocurrir que interpretaran "lo razonable" en base a "lo ordinario". Aunque ello fuera así, en cualquier caso, este hecho en principio no constituiría una objeción al estándar; más bien, se trataría de una objeción al trabajo de los tribunales ${ }^{17}$.

En segundo lugar, el reino de los fines es el de la racionalidad instrumental, el de la capacidad de formar, revisar y perseguir racionalmente una concepción de lo bueno. Para que las personas podamos interactuar en una sociedad organizada como un reino de fines, necesitamos reglas públicas que nos permitan coordinar. E1 reino de lo subjetivo debe exteriorizarse para que podamos coordinar nuestras acciones. En el derecho de los contratos, quizá cada una de las partes en el contrato tenga un entendimiento subjetivo del acuerdo. Si ello es así, en caso de que las partes tuvieran algún desacuerdo en un contrato, siempre habría dos subjetividades compitiendo por imponerse. Sin embargo, los contratos son esfuerzos cooperativos de dos o más partes. Por ello, para determinar si existe un acuerdo, o cuál es el contenido del acuerdo, el derecho generalmente adopta un estándar objetivo, basado en cómo puede interpretarse la conducta o las palabras de las partes en el contexto particular en el que interactúan. Por ejemplo, en algunas circunstancias, la conducta de una persona puede ser tomada por otra como indicativa de la expresión de la voluntad de vincularse contractualmente. Como explico en el libro, mi propuesta no niega que el consentimiento sea el aspecto central de un contrato. No obstante, el consentimiento también es objetivo.

${ }^{17}$ Hevia, Reasonableness... op. cit. 
Martín Hevia

El consentimiento de las partes no depende de que las partes hayan pensado que habían celebrado un contrato. Más bien, tanto la existencia como el contenido de los acuerdos se determinan a través, y solo a través, de la interacción entre las partes. Así, para interpretar si A y B tienen un contrato, el derecho se pregunta si, en el contexto específico de la interacción entre las personas involucradas, es razonable para A - o para $\mathrm{B}$ respecto de $\mathrm{A}$ - asumir que la contraparte se ha comportado de un modo tal que su conducta ha generado la expectativa razonable de vincularse contractualmente. Ahora bien, si tengo razón, contra la sugerencia de Rengifo Gardeazábal, este modo de entender las interacciones contractuales no me compromete con una visión utilitarista: no es que solo habrá contrato cuando la interacción pueda considerarse socialmente valiosa; hay contrato cuando las partes hacen -o dejan de hacer - aquello que pueda razonablemente ser interpretado como la expresión de voluntad de vincularse jurídicamente.

\section{Segunda parte: el derecho contractual vigente}

En esta segunda parte, me ocuparé de las objeciones que comparten los tres comentaristas: mi teoría no explica una parte importante del derecho contractual: los contratos de adhesión y las cláusulas generales de contratación; tampoco explica las diversas ocasiones en las que el derecho contractual obliga a los jueces a realizar consideraciones de justicia distributiva - por ejemplo, cuando los tribunales se enfrentan a casos que presentan un supuesto de lesión enorme o lesión subjetiva/objetiva-. Papayannis, por ejemplo, como mencioné antes, sostiene que los derechos y obligaciones de las partes de un contrato no son siempre resultado de la autoridad normativa de las partes: si las partes quieren contratar, deben aceptar algunas reglas de orden público, de las que no pueden apartarse ${ }^{18}$. En la misma línea, Rengifo Gardeazábal concentra sus objeciones en las teorías contractuales en general; a su juicio, los contratos no son más un instrumento al servicio de la libertad de las partes porque la aparición y el desarrollo 
tanto de las condiciones generales de contratación como de las situaciones contractuales de hecho ha limitado la libertad de elegir el contenido de las cláusulas contractuales. Para Rengifo Gardeazábal, "ni el modelo kantiano ni el modelo supuestamente neokantiano de las expectativas razonables se adaptan claramente a las nuevas realidades contractuales"19. Por su parte, De la Maza Gazmuri sostiene que mi teoría no explica la existencia de los contratos de adhesión: en la contratación moderna, el derecho tiene en cuenta la asimetría de información entre las partes, que pone en peligro el ejercicio de la racionalidad instrumental que mi teoría presupone. Esta circunstancia ha llevado al desarrollo de los contratos de adhesión, que suelen estar regulados para evitar el abuso a los consumidores. Al mismo tiempo, ya no es cierto que los contratos sean fruto de una negociación entre las partes: los términos de los contratos de consumo son impuestos unilateralmente por una de las partes; el consumidor puede aceptar o rechazar los términos, pero si los rechaza, no habrá contrato. En todo caso, podría ser cierto que existe la libertad para contratar, pero no la de elegir el contenido de las cláusulas del contrato ${ }^{20}$.

Sobre la base de estas objeciones, Rengifo Gardeazábal sostiene que, si son honestos intelectualmente, los teóricos neokantianos del derecho contractual - entre quienes estoy incluido - o bien deben aceptar que su teoría no explica la realidad contractual moderna, o bien deben revisar sus teorías ${ }^{21}$. Pienso que estas observaciones son muy pertinentes pues, en efecto, la teoría que desarrollo en Reasonableness and Responsibility no da cuenta ni de los contratos de adhesión ni de las cláusulas generales de contratación, aunque sí podría explicar las relaciones contractuales de hecho. Comenzaré con este último punto relacionado con las relaciones de hecho. Luego, en respuesta a las objeciones, aprovecharé la ocasión para esbozar en la sección siguiente una respuesta, que conlleva revisar los fundamentos de la teoría. Veamos.

${ }^{19}$ Rengifo Gardeazábal, M., op. cit.

${ }^{20}$ De la Maza Gazmuri, I., "Razonabilidad...", op. cit.

${ }^{21}$ Rengifo Gardeazábal, M., op. cit. 
Martín Hevia

\section{IV.1. Las relaciones contractuales de hecho}

Rengifo Gardeazábal sostiene que las teorías neokantianas no pueden dar cuenta de las relaciones contractuales de hecho, que comprenden los servicios públicos domiciliarios, el transporte público, y las operaciones de comercio electrónico, entre otros. Estos contratos no surgen como consecuencia de una decisión de personas que deciden contratar para promover sus fines; tampoco hay una negociación entre personas que eligen los términos de un acuerdo que les resultan más convenientes. Antes bien, en estos contratos, las obligaciones de las partes surgen como consecuencia de conductas sociales típicas, sin necesidad de intercambio de información entre las partes. Es más, en estos escenarios, el contrato ni siquiera puede anularse por error; basta con la conducta típica para que tengamos contrato ${ }^{22}$. Rengifo Gardeazábal explica muy bien que las relaciones contractuales pueden surgir como consecuencia de: 1. un deber social de prestación (como en el uso de un servicio público domiciliario, con tarifas preestablecidas por las autoridades); 2. por la inserción en una comunidad organizada (como en las sociedades de hecho); 3 . por el contacto social (como el transporte benévolo); o 4. por la interacción con mecanismos automatizados (con dispensadoras de productos o servicios como compra de boletos de tren). En estos escenarios, según Rengifo Gardeazábal, aunque sin duda estamos ante contratos, no hay libertad de no contratar y, en consecuencia, no tiene sentido sostener que hay libertad contractual ${ }^{23}$.

Ante esta realidad, no tiene sentido para el teórico neokantiano negar que las situaciones contractuales de hecho no son contratos porque ello significaría negar la evidencia que no favorece su posición, lo que sería deshonesto de su parte ${ }^{24}$. Alternativamente, los neokantianos podrían sostener que, en verdad, dado que presuponen conductas libres y conscientes, la regulación de las situaciones requiere del reconocimiento de un "reducto de libertad mínima" — de hecho, si hubiese violencia física o intimidación moral, la víctima

22 Ídem.

${ }^{23}$ Ibídem.

$158 \quad{ }^{24}$ Ibídem. 
podría solicitar la anulación del contrato- No obstante, Rengifo Gardeazábal responde que ello no representa el tipo de libertad entendida como regulación de la conducta propia con la que es habitual asociar la libertad contractual, es decir, la libertad de conclusión y la libertad de configuración de un contrato ${ }^{25}$.

Ahora bien, contra la objeción de Rengifo Gardeazábal, entiendo que mi teoría podría dar cuenta de las situaciones contractuales de hecho. Estas presuponen una declaración tácita de la voluntad. El agente se comporta de una cierta forma y, sobre la base de esa conducta, el derecho asigna una voluntad de vincularse contractualmente. Esto no está muy alejado de sostener que los contratos pueden concluirse tácitamente, es decir, no es necesario que, en todos los casos, exista una negociación entre las partes. Tradicionalmente, los sistemas jurídicos han reconocido que es posible inferir de una acción o incluso de una omisión, según el contexto, una voluntad de vincularse contractualmente ${ }^{26}$. Mi teoría de los contratos no supone que todos los contratos requieren de una negociación entre las partes; estos también pueden surgir como consecuencia de conductas que, en un contexto determinado, pueden interpretarse razonablemente como expresión de una voluntad de vincularse. En esos casos, el derecho infiere que, si el agente no quisiera vincularse contractualmente, se hubiera comportado de otra manera. En el caso de las situaciones contractuales de hecho, es todavía más sencillo entender por qué determinadas conductas pueden vincularnos contractualmente: las conductas libres que dan lugar a situaciones contractuales de hecho - es decir, a contratos - son conductas típicas, cuyo significado social está determinado (por ejemplo, subir a un autobús o ingresar a un vagón de tren: aunque la persona involucrada suba a un transporte público sin la intención de ser transportado, debe pagar el boleto

\section{${ }^{25}$ Ibídem.}

${ }^{26} \mathrm{La}$ conducta de las partes tiene un papel tan importante que puede ser utilizada como criterio para interpretar la voluntad de las partes. Algunos tribunales en la Argentina han reconocido que las interacciones anteriores a la celebración del contrato también pueden ser utilizadas como criterio para interpretar el contrato. 
como el resto de los pasajeros). Mi teoría podría dar cuenta de las situaciones contractuales de hecho como las sociedades de hecho o el transporte benévolo. También, a mi juicio, podría dar cuenta de las situaciones contractuales de hecho que surgen como consecuencia de un deber social de prestación o de la interacción con mecanismos automatizados. Veamos.

En la sociedad moderna, el hecho de que muchos bienes y servicios se ofrezcan de un modo masivo es una oportunidad para las personas que desean perseguir ciertos planes. Los costos de transacción involucrados en las negociaciones contractuales harían que, si no pudieran ofrecerse de este modo, muchos bienes y servicios no se ofrecerían. En este contexto, es razonable asumir que las personas deban aceptar que, en ciertas circunstancias, su conducta pueda vincularlos contractualmente, aun cuando no haya habido posibilidad de negociar las cláusulas del contrato. Es también razonable asumir que una persona que sube a un autobús o a un vagón de tren lo hace para ser transportado y que, por ello, debe pagar el boleto correspondiente. Es justo que aceptemos estos términos de interacción social o, caso contrario, resultaría muy difícil coordinar las interacciones sociales.

Rengifo Gardeazábal podría objetar que mi teoría también debe explicar por qué en las situaciones contractuales de hecho las personas no pueden invocar dolo o error, algo que sí pueden hacer cuando el contrato se forma como consecuencia de una negociación entre partes. Pues bien, es cierto que el consumidor no puede alegar dolo o error si compra la bebida equivocada en una máquina dispensadora de bebidas, o que el pasajero no puede alegar que no conocía que el transporte público era pago. No obstante, las normas de defensa del consumidor protegen a los consumidores en las circunstancias en las que razonablemente puede asumirse que la asimetría de información entre las partes pone al consumidor en una situación de inferioridad en relación con el proveedor de un servicio. Esta inferioridad podría derivar en errores razonables del consumidor (por ejemplo, por no leer la letra chica de un contrato de prestación de un servicio de telefonía celular) o en aprovechamiento (como cuando ocurre cuando la prestadora incluye multas por retrasos en el cumplimiento de la obligación 
de pago a cargo del consumidor). En ese tipo de casos, la razonabilidad podría utilizarse como criterio, del mismo modo en que, a mi juicio, se utiliza en los códigos civiles cuando se trata de determinar si un determinado tipo de error puede dar o no lugar a un pedido de nulidad de la parte que cometió el error (así, por ejemplo, no cualquier error es causa de nulidad; debe tratarse de un error excusable. Para determinar si el error es excusable, los tribunales se preguntan si es razonable que, en las circunstancias en que el agente se encuentra, pueda cometer un error).

En suma, las herramientas teóricas de Reasonableness and Responsibility permitirían dar cuenta de las situaciones contractuales de hecho. Esta respuesta y, en especial, mi referencia a los contratos de consumo, no obstante, podría no ser satisfactoria. En la sección siguiente me concentraré en los contratos de adhesión con consumidores y en si mi teoría dispone de herramientas para explicarlos.

\section{IV.1.1. Racionalidad y contratos de consumo}

El punto de partida de mi teoría en Reasonableness and Responsibilitis es la concepción de la persona. Según expliqué, siguiendo a Rawls, mi teoría presupone que las personas somos tanto racionales como razonables. La racionalidad hace referencia a la capacidad de formar, revisar y perseguir racionalmente una concepción de lo bueno. Esta capacidad está asociada con la noción de racionalidad instrumental, es decir, con el homo economicus, que siempre elige los medios más efectivos para perseguir sus planes, cualesquiera sean. Por su parte, la razonabilidad de las personas implica una capacidad de entender, de poner en práctica y de actuar motivado por - y no solo de conformidad con- los principios de justicia política que especifican los términos justos de cooperación social. Según expliqué, el derecho contractual refleja ambas capacidades o poderes morales. Así, los contratos son herramientas para perseguir nuestros planes, intercambiando bienes o servicios. Dada nuestra racionalidad, si no deseáramos celebrar un determinado contrato porque no nos resulta conveniente, por ejemplo, no lo haríamos. A su vez, según expliqué, dado que también somos 
Martín Hevia

razonables, aceptamos sujetarnos a reglas comunes que regulan nuestras interacciones. El derecho contractual es el conjunto de reglas que establece tanto las condiciones en las que nos obligamos jurídicamente a intercambiar bienes o servicios, como los efectos de incumplir los acuerdos que celebramos. Como bien señala De la Maza Gazmuri, mi teoría está en problemas porque la existencia de los contratos de adhesión que suelen celebrar consumidores y proveedores o vendedores pone a prueba la idea de racionalidad instrumental. En este tipo de contratos no hay una negociación; el consumidor o bien acepta las cláusulas ofrecidas por el proveedor, o bien no lo hace y entonces no se celebra el contrato ${ }^{27}$. Para el consumidor, obtener información para tomar una decisión racional implica $\operatorname{costos}^{28}$. De acuerdo con la idea de racionalidad instrumental, el consumidor debería obtener información antes de celebrar un contrato cuyos términos no puede negociar. Así, antes de comprar un coche o un inmueble, el comprador se informará acerca de la calidad del bien, sobre la garantía, etc. Informarse no es gratis: requiere invertir tiempo y, en algunos casos, recursos. La cantidad de información que obtendrá y el tiempo que invertirá para obtenerla dependerán del valor esperado de la inversión que realizará para obtener el bien ${ }^{29}$. Los contratos de adhesión involucran dos tipos de productos, a saber, la prestación y el contrato en sí mismo. Si el agente es racional, debería acumular información sobre ambos. No obstante, los consumidores no invierten en entender el contenido del contrato porque el costo de hacerlo es superior al beneficio que obtienen con la celebración del contrato. Es decir, la decisión de no leer el contrato es racional. Hasta allí, no se presentan desafíos porque, en todo caso, el agente que no lee el contrato lo hace intencionalmente. Podría defenderse la idea de que el consumidor debería hacerse cargo de su decisión de no invertir tiempo en leer y en entender las cláusulas que no negoció. Es probable que, debido a esta decisión, los oferentes puedan incluir cláusulas que el consumidor no aceptaría si hubiese

27 De la Maza Gazmuri, I., "Razonabilidad...", op. cit.

${ }^{28}$ En este punto, sigo a De la Maza Gazmuri, I., Contratos Por Adhesión..., op. cit.

${ }^{29}$ Ibídem, págs. 15-21. 
leído el contrato. La doctrina llama "cláusulas abusivas" a este tipo de cláusulas, que son desfavorables al consumidor de un modo exagerado. Este tipo de cláusulas pueden pasar desapercibidas ${ }^{30}$. Los consumidores, de hecho, apelarán a la información menos costosa para elegir entre los productos, es decir, probablemente apelarán al precio. Los proveedores, entonces, no aumentarán el precio, pero incorporarán cláusulas que trasladen riesgos hacia el consumidor, que elegirá productos con el precio más bajo, pero sin saber que el contrato para adquirirlos incluirá cláusulas que lo perjudican. Ante esta realidad, los sistemas jurídicos reaccionan protegiendo al consumidor. En algunas jurisdicciones existen leyes de defensa al consumidor que establecen que las cláusulas "abusivas" deben interpretarse a favor del consumidor, que el proveedor está obligado a otorgar garantías -incluso si el producto es usado-, y así. En otras jurisdicciones, por ejemplo en Francia, los contratos de adhesión están sujetos a un control administrativo. Así, como explica De la Maza Gazmuri, existen catálogos de cláusulas abusivas que sirven como herramientas para que los tribunales puedan examinar y modificar, si correspondiese, las cláusulas abusivas en base a la idea de buena $\mathrm{fe}^{31}$.

Como explican De la Maza Gazmuri y Rengifo Gardeazábal en sus comentarios, una alternativa sería sostener que este tipo de contratos, en realidad, no son contratos. Esa respuesta, no obstante, no sería apropiada, especialmente teniendo en cuenta que, en la actualidad, la mayoría de los contratos que celebramos casi diariamente son contratos de este tipo ${ }^{32}$. Dada la pretensión de que mi teoría es una teoría interpretativa, si quiere dar cuenta de esta práctica contractual, debe explicarla. Al hacerlo, como explica Papayannis en su comentario, si acepto que los tribunales están facultados a modificar las cláusulas de un contrato invocando consideraciones externas a la relación entre las partes, parecería necesario renunciar a mi idea de que el derecho contractual es el ámbito de la justicia correctiva y no

${ }^{30}$ Ibídem, pág. 32.

${ }^{31}$ Ibídem, pág. 32.

${ }^{32}$ De la Maza Gazmuri, I., "Razonabilidad...”, op. cit. y Rengifo Gardeazábal, M., op. cit. 
de la justicia distributiva: al evitar que los proveedores se abusen del hecho de que los consumidores contarán con menos información y que no podrán negociar términos alternativos, el derecho contractual incluye consideraciones de naturaleza distributiva ${ }^{33}$.

Quizá en la misma línea de objeción, podría sumarse la crítica formulada por Sunstein y Thaler en su famoso libro Nudge $e^{34}$ : la idea de racionalidad instrumental — que mi teoría asume - es defectuosa porque asume que las personas son "econs", que pueden acumular cantidad infinita de información, que la usarán apropiadamente al tomar decisiones y que tienen un poder de voluntad inquebrantable que les permite, en todos los casos, actuar racionalmente. En el mundo real, no obstante, las personas son "humans": cometen errores a diario y, muchas veces, aunque sepan cuál es la decisión y el curso de acción correcto en función de sus intereses, no tienen la fuerza de voluntad para ponerlos en práctica. Por ejemplo, ya sean porque son vagos, por miedo o por distracción, las personas elegirán el curso de acción que les demande menos esfuerzo. Sunstein y Thaler sostiene que nuestras instituciones deberían tener especialmente en cuenta el hecho de que los humans cometen errores. Así, desarrollan la idea de "arquitectura de la decisión" - "choice architecture"-: al diseñar instituciones y legislar, deberíamos tener en cuenta nuestra falibilidad para tomar decisiones racionales. De hecho, los proveedores de servicios ya son muy conscientes de la naturaleza humana. Por ejemplo, un contrato de suscripción a una revista podría incluir una cláusula de renovación automática de la suscripción —-mucha gente que no lee la revista se suscribiría por tiempo indefinido- - Los legisladores deberían diseñar normas que ofrezcan incentivos para que las personas tomemos decisiones informadas. Sunstein y Thaler llaman a su visión "paternalismo libertario" porque, si bien es respetuoso de la autonomía de las personas, entienden que las normas deberían incentivar de diferentes

\footnotetext{
${ }^{33}$ Papayannis, D., op. cit.

${ }^{34}$ Sunstein, C.S. y Thaler, R. H., Nudge. Impoving Decisions About Health, Wealth, and Happiness, New Haven, Yale University Press, 2008.
} 
formas a los consumidores a que se informen antes de tomar decisiones que podrían perjudicarlos ${ }^{35}$.

Todas estas observaciones llevan a la conclusión de que, para dar cuenta de la práctica del derecho contractual, mi teoría debe ser revisada. En la siguiente sección, presento algunas observaciones al respecto.

\section{Racionalidad, razonabilidad y teoría del derecho contractual}

A la luz de la discusión en la sección anterior, resulta difícil sostener una teoría del derecho contractual basada exclusivamente en la mera y formal manifestación de la voluntad. Según expliqué, el reconocimiento de la existencia de asimetría de información entre las partes lleva a la regulación de los contratos de adhesión con los consumidores (y podría explicar, también, la lesión). Ello significa que, para resolver controversias acerca de este tipo de acuerdos, los tribunales están autorizados a revisar el contenido de los contratos apelando a consideraciones externas a los valores de las partes. Ahora bien, ¿qué consecuencias conlleva este reconocimiento para mi teoría del derecho contractual?

Quizá, este modo de ver el derecho contractual me acerque a la lectura de Kronman propuesta por Papayannis, en particular, a su primera tesis: la plausibilidad moral del derecho contractual depende de que los contratos no representen un aprovechamiento inaceptable de una parte a la otra ${ }^{36}$. Kronman usa esta idea para explicar qué es lo que dota de fuerza normativa a la expresión de la voluntad de las personas, es decir, qué condiciones deben satisfacerse para que podamos sostener que dos o más personas han celebrado un contrato. Quizá también esta idea pueda usarse para evaluar la validez de cláusulas específicas de los contratos de consumo, sin que ello signifique la invalidez del contrato completo. Como he mostrado, nuestra racionalidad nos lleva en muchos casos a no adquirir información, o a hacer

${ }^{35}$ Ídem.

${ }^{36}$ Papayannis, D., op. cit. 
cálculos equivocados con la información que disponemos, lo que puede ser aprovechado por la contraparte en una interacción. En otras palabras, una teoría del derecho contractual que toma como presupuesto la racionalidad instrumental debería derivar en instituciones de derecho contractual diseñadas teniendo en mente el hecho de que antes que econs, las personas somos humans. Por supuesto, el derecho contractual también debería dar incentivos para que los proveedores ofrezcan productos. Por ejemplo, quizá el derecho contractual no deba permitir que los tribunales puedan modificar por razones de justicia distributiva el precio de un bien; el consumidor bien podría elegir otro. Si no fuera así, probablemente los oferentes de bienes y servicios dejarían de ofrecerlos debido a la incertidumbre que les generaría la posibilidad de que el precio sea modificado. No obstante, tal como sucede en las leyes sobre defensa del consumidor, dada la probabilidad de que los proveedores se aprovechen de la racionalidad limitada de los consumidores, quizá dichas normas no deban permitir que las personas puedan aceptar contratos en los que renuncian a la facultad de presentar una demanda civil por defectos en el producto. Alternativamente, quizá ese tipo de cláusulas de renuncia no deba aceptarse porque no deseamos que los consumidores pierdan la opción de presentar demandas civiles. Ello también puede comprometerme con la segunda tesis de Kronman: el derecho contractual puede ser utilizado para promover fines distributivos o redistributivos, aunque sea de un modo modesto. Ahora bien, como explica Papayannis, "una vez que las partes adhieren al sistema de intercambio, el incumplimiento y los remedios sí pueden ser explicados por la justicia correctiva. Pero ello limita significativamente el carácter privado de los contratos..."37.

\section{Palabras finales}

En esta respuesta a mis críticos he seguido el siguiente orden. Siguiendo la sugerencia de De la Maza Gazmuri, comencé clasificando a mi teoría como teoría interpretativa del derecho contractual. 
Este tipo de teorías tienen por objetivo explicar el derecho vigente a la luz de ideales normativos. Los artículos de mis críticos se concentran tanto en el fundamento normativo de mi teoría como en el hecho de que esta no explica el derecho contractual vigente. En la primera sección del trabajo, me concentré en las críticas de Papayannis y Rengifo Gardeazábal al fundamento normativo de mi teoría. En mis respuestas, expliqué en qué sentido mi teoría es diferente de la de los libertarios; también intenté mostrar que el énfasis en el reino de los fines kantiano no es incompatible con una concepción objetivista de la formación contractual. En la segunda parte del trabajo traté la crítica compartida por los tres comentaristas: la teoría que desarrollo en Reasonableness and Responsibility no da cuenta del derecho contractual vigente, en particular, de las relaciones contractuales de hecho y de los contratos de adhesión. En mi respuesta, sugerí que la teoría sí puede dar cuenta de las relaciones contractuales de hecho. En cambio, mi énfasis en el carácter privado y de justicia correctiva del derecho contractual me priva de la posibilidad de dar cuenta de los contratos de adhesión. En el caso de los contratos de adhesión, nos preocupa si, dado que los consumidores no leemos todas sus cláusulas, la asimetría de información entre proveedores y consumidores pueda derivar en un escenario de "aprovechamiento injusto sistémico" de la situación de los consumidores. Como explica Papayannis, mi teoría, en definitiva, debería tener que aceptar que, si bien el derecho contractual es derecho privado porque deja en mano de los particulares la decisión de vincularse contractualmente o de no hacerlo, puede al mismo tiempo ser utilizado para promover objetivos sociales valiosos - este caso, es un objetivo social valioso permitir que las personas puedan intercambiar bienes y servicios, pero sin que haya un aprovechamiento abusivo basado en la asimetría de información-. Agradezco nuevamente a mis comentaristas por sus valiosos análisis y espero en el futuro poder honrar sus comentarios desarrollando en más detalle el fundamento del derecho contractual. 
Martín Hevia

\section{Bibliografía}

De la Maza Gazmuri, I., "Contratos por adhesión y cláusulas abusivas: ¿Por qué el Estado y no solamente el mercado? Revista Chilena de Derecho Privado, Fernando Fueyo Laneri, 2003.

De la Maza Gazmuri, I., "Razonabilidad y responsabilidad: A propósito de la teoría del derecho contractual del profesor Martín Hevia”. Discusiones, XV, 2014, págs. 85-100.

Gordley, J., Foundations of Private Law, Cambridge: Oxford University Press, 2006.

Gordley, J., The Philosophical Origins of Modern Contract Doctrine, Cambridge: Oxford University Press, 1991.

Hevia, M., Reasonableness and Responsibility: A Theory of Contract Law, Dordrecht, Springer, 2012.

Nozick, R., Anarchy, State, and Utopia, Basic Books, Nueva York, 1973.

Papayannis, D., "La insportable levedad de la justicia correctiva en el derecho contractual". Discusiones, XV, 2014, págs. 101-144.

Papayannis, D., "Teorías de la responsabilidad extracontractual", en Hevia, M., Teoría y Crítica del Derecho Civil y Comercial, Fontamara, México, 2012.

Rawls, J., Justice as Fairness - A Restatement, The Belknap Press of The Harvard University Press, Cambridge, Massachussets, 2001.

Rengifo Gardeazábal, M., "Teoría del contrato, libertad y determinismo social: La Posición Incompatibilista". Discusiones, XV, 2014, págs. 49-84.

Rengifo Gardeazábal, M., Teoría General de la Propiedad, Temis, Bogotá, 2011.

Smith, S., Contract Theory, Cambridge, Oxford University Press, 2004. Sunstein, C. S. y Thaler, R. H., Nudge. Impoving Decisions About Health, Wealth, and Happiness, New Haven: Yale University Press, 2008. 